\title{
O PROJETO PEDAGÓGICO INSTITUCIONAL (PPI) DO IFSC 2015-2018: UMA ANÁLISE ENTRE O PROCLAMADO E $O$ REALIZADO, A PARTIR DA SUA CONCEPÇÃO EDUCATIVA HISTÓRICO-CRÍTICA, DEMOCRÁTICA E EMANCIPADORA
}

\author{
Evandro Belmiro da Silva*, Adriano Larentes da Silva \\ ${ }^{*}$ E-mail: evandro.belmiro@ifsc.edu.br \\ Instituto Federal de Educação Profissional, Científica e Tecnológica de Santa Catarina, Brasil \\ DOI: $10.15628 /$ rbept.2020.8755 \\ Artigo submetido em jun/2019 e aceito em mar/2020
}

\begin{abstract}
RESUMO
A Lei n. $.013 .415 / 2017$, sobre a Reforma do Ensino Médio, apresenta-se como uma ameaça ao projeto educativo do Ensino Médio Integrado (EMI). No presente artigo, com foco na análise do Projeto Pedagógico Institucional (PPI), busca-se compreender a materialidade das contradições, por meio do discurso textual, entre o proclamado e o realizado, tendo como referência a concepção histórico-crítica. Para isso, faz-se uso dos recursos da análise documental e pesquisa bibliográfica, com abordagem no materialismo histórico dialético. Por fim, a partir da análise dos projetos dos cursos técnicos de nível médio, na sua forma integrada, constata-se evidências preliminares do distanciamento entre a concepção educativa institucional e os projetos de curso do EMI, o que ajuda a compreender os limites de uma resistência da comunidade acadêmica frente a atual Reforma do Ensino Médio.
\end{abstract}

Palavras-chave: Projeto Pedagógico Institucional; Ensino Médio Integrado; Concepção Histórico Crítica.

\section{THE INSTITUTIONAL PEDAGOGICAL PROJECT (PPI) OF THE IFSC 2015-2018: AN ANALYSIS BETWEEN THE PROCLAMATE AND THE CONDUCTED, FROM HIS HISTORICAL-CRITICAL, DEMOCRATIC AND EMANCIPATORY EDUCATIONAL CONCEPTION}

\begin{abstract}
Law $n . .13,415$ / 2017, on the Reform of Secondary Education, presents itself as a threat to the educational project of Integrated Higher Education (EMI). In this article, focusing on the analysis of the Institutional Pedagogical Project (PPI), we seek to understand the materiality of the contradictions, through the textual discourse, between the proclaimed and the realized, with reference to the historical-critical conception. For this, the resources of documentary analysis and bibliographical research are used, with an approach in dialectical historical materialism. Finally, from the analysis of the projects of the middle-level technical courses, in its integrated form, there is preliminary evidence of the distance between the institutional educational conception and the EMI course projects, which helps to understand the limits of a resistance of the academic community to the current High School Reform.
\end{abstract}

Keywords: Institutional Pedagogical Project; Integrated High School; Critical Historical Design. 
Ninguém caminha sem aprender a caminhar, sem aprender a fazer o caminho caminhando, refazendo e retocando o sonho pelo qual se pôs a caminhar.

Paulo Freire

\section{INTRODUÇÃO}

A partir do Decreto no. 5.154/2004, outros dispositivos legais foram criados no campo da Educação Profissional e Tecnológica para fortalecer a concepção educativa de formação integrada. Com a criação dos Institutos Federais de Educação, Ciência e Tecnologia, por meio da Lei n. 11.892/2008, dentre diversas possibilidades educativas, priorizou-se a oferta dos Cursos Técnicos de Nível Médio, na sua forma integrada, (BRASIL, 2004). Esse arcabouço legal significou um importante avanço da proposta de formação integrada, compreendida enquanto política pública, numa perspectiva de superação do dualismo histórico entre a educação básica e a educação profissional. Porém, os avanços legais, apesar de importantes, não são suficientes para concretização de um novo projeto educativo. Segundo Ciavatta (2005, p. 01), "as palavras podem ser ditas, as imagens podem ser mostradas, as coisas acontecem se há vontade política e meios ou recursos, e se elas têm legitimidade perante a opinião pública".

Desde o marco de criação dos Institutos Federais, mudanças políticas no âmbito do governo ocorreram, e atualmente, o seu projeto de formação integrada está ameaçado pela Lei $n$ 우 13.415/2017, que trata sobre a Reforma do Ensino Médio, a qual impõe aos filhos da classe trabalhadora a redução do direito de acesso aos conhecimentos historicamente produzidos e acumulados pela humanidade, numa perspectiva de fortalecimento do dualismo histórico entre a educação básica e a educação profissional. $\mathrm{Na}$ atual conjuntura, o projeto de formação integrada do Ensino Médio Integrado (EMI), anunciado pelo Decreto n. 5.154/2004 que revogou a extinção da articulação entre o ensino médio e o ensino técnico, na sua forma integrada, e fortalecido pela lei de criação dos Institutos Federais, precisa de uma ampla resistência da comunidade acadêmica, em defesa das suas bases conceituais para uma formação mais ampla dos jovens trabalhadores, que nos dizeres de Ramos (2008) considere as dimensões da vida no seu processo formativo, como o trabalho, as ciências e a cultura.

No Instituto Federal de Educação Profissional, Científica e Tecnológica (IFSC), após quase um ano da promulgação da Lei no 13.415/2017, até o momento, observa-se uma indefinição por parte da instituição para assumir um posicionamento claro frente a questão da reforma. Mas afinal, como a concepção educativa do IFSC nos orienta para responder a essa questão? Diante do atual dilema, entre o conformismo/adaptação e a resistência à Reforma do Ensino Médio, assim como a constatação de que o projeto pedagógico institucional não serviu de referência para essa tomada de decisão, tendo em vista a sua concepção educativa, este artigo retoma a concepção educativa histórico-crítica, explicitando a sua coerência com o projeto educativo do EMI, em seu significado mais amplo, de forma a promover uma educação 
orientada para as reais necessidades dos trabalhadores. Aprofunda-se a compreensão acerca dos pressupostos teóricos metodológicos da concepção educativa, observando a sua coerência e inconsistência no documento. Com foco na análise do documento PPI, busca-se compreender a materialidade das contradições, por meio do discurso textual, entre o proclamado e o realizado. Para isso, faz-se uso dos recursos da análise documental e pesquisa bibliográfica, com abordagem no materialismo histórico dialético.

Na seção, intitulada "O processo de construção do Projeto Pedagógico Institucional (PPI) do IFSC", busca-se refletir sobre as possibilidades e limites da metodologia adotada, assim como sobre a relativa autonomia pedagógica da instituição, diante da(s) influência(s) que os documentos oficiais das políticas públicas em educação têm no processo de construção do PPI.

Nas seções, respectivamente intituladas "Os pressupostos teóricos da Pedagogia Histórico-Crítica" e "A concepção do Ensino Médio Integrado", aprofunda-se as bases conceituais dessa corrente pedagógica brasileira e explicita-se a sua coerência com o projeto educativo do EMI, na perspectiva de uma formação de qualidade para os jovens trabalhadores.

$\mathrm{Na}$ seção intitulada "Metodologia" trata-se do uso dos recursos da análise documental e pesquisa bibliográfica, com abordagem no materialismo histórico dialético. Na seção intitulada "Resultados e discussões: entre o proclamado e o realizado", analisa-se as contradições internas à formulação do $\mathrm{PPI}$, identificando as vozes discordantes que se manifestam e/ou silenciam. Nessa seção, também analisa-se os projetos de cursos técnicos integrados do IFSC, criados e/ou reestruturados entre os anos de 2015 e 2018, observandose a menção que deram à concepção educativa do PPI.

Por fim, nas considerações finais, reflete-se sobre a perspectiva de fortalecimento do projeto educativo EMI, a partir da compreensão das suas bases conceituais, em consonância com os interesse dos trabalhadores. Assim como, busca-se compreender os limites da construção da resistência na atual conjuntura.

\section{O PROCESSO DE CONSTRUÇÃO DO PROJETO PEDAGÓGICO INSTITUCIONAL (PPI) DO IFSC}

O projeto pedagógico de uma instituição educativa, parafraseando o educador Paulo Freire, deve ser compreendido como a materialização de um sonho pelo qual a comunidade acadêmica se pôs a caminhar. Nos dizeres de Veiga (1998, p. 09), o projeto pedagógico "exige profunda reflexão sobre as finalidades da escola" e a "clara definição de caminhos, formas operacionais e ações a serem empreendidas por todos os envolvidos com o processo educativo". Nesse sentido, todo projeto pedagógico deve ser analisado de forma mais ampla, nas suas contradições, considerando as influências de fatores e tensões, tanto internos quanto externos. Conforme argumenta Veiga:

Nesse ato de trilhar em direção à qualidade do processo educativo, destacamos, de um lado, a importância de refletir 
sobre as relações mais amplas da escola com as políticas públicas alicerçadas na visão estratégica; de outro, buscamos compreender os pressupostos que devem embasar a construção do projeto político-pedagógico da instituição educativa na visão emancipadora (VEIGA, 2001, p. 46).

A elaboração do projeto pedagógico do IFSC sofreu influência externa dos documentos oficiais das políticas públicas em educação. O Projeto Pedagógico Institucional (PPI) do IFSC, não foi construído por espontâneo desejo dos gestores da instituição, tampouco como reivindicação intencional da sua comunidade acadêmica, mas por razão de uma exigência legal. Sobre isso, a nova LDB, Lei $n^{\circ}$ 9.394/96, prevê no seu art. 12, inciso I, que "os estabelecimentos de ensino, respeitadas as normas comuns e as do seu sistema de ensino, terão a incumbência de elaborar e executar sua proposta pedagógica". No caso das instituições com oferta educativa para cursos superiores, como o IFSC, há uma exigência do Decreto 5.773/2006, que prevê a elaboração do Plano de Desenvolvimento Institucional (PDI), sendo o PPI (IFSC, 2013, p. 8) um dos seus documentos integrantes que "manifesta o ideal de educação, que registra o processo de construção da identidade institucional e que dá suporte para a avaliação das ações educativas programadas pela instituição".

Sobre a metodologia adotada para elaboração do documento, o início dos trabalhos deu-se no mês de maio de 2013, por meio do Seminário do PPI, quando os participantes do evento, indicados pelos diversos câmpus, elaboraram uma versão comentada do PPI vigente, assim como deliberaram pela criação de comissões temáticas, que ficaram responsáveis pela organização das contribuições dos grupos e redação de uma minuta do PPI. A partir da minuta, nos diversos câmpus, as comissões locais realizaram discussões para formulação de propostas que compuseram o documento base para assembleia do PPI, apreciado por toda a comunidade acadêmica no mês de setembro daquele ano. No processo de elaboração do PPI do IFSC, sob a orientação da comissão central, todas as proposições ao texto deveriam estar em consonância com os documentos de referência da política pública educacional.

Considerando o caráter estratégico do PDI, conforme Decreto $5.773 / 2006$, assim como o fato do processo ter sido coordenado pela Próreitoria de Desenvolvimento Institucional, cujos servidores possuem experiência e formação na área da administração, criou-se a expectativa inicial do documento ser construído, imbuído de sua dimensão predominantemente técnica, em detrimento da sua dimensão político-pedagógica expressa pelo PPI. Segundo Veiga (2001, p. 47), o projeto político-pedagógico do ponto de vista estratégico empresarial é concebido como "[...] um instrumento de controle, por estar atrelado a uma multiplicidade de mecanismos operacionais, de técnicas, de manobras e estratégias [...]".

Porém, a partir do fato de os autores desse artigo terem sido sujeitos do processo, um deles, inclusive, participando como membro da comissão temática para elaboração da minuta do PPI, pode-se constatar um contraponto a essa visão estratégico empresarial do PDI, de forma a atuar como fator de 
tensão interna. No âmbito da Comissão Central, alguns sujeitos atuaram na perspectiva do PPI ser construído sob o ponto de vista emancipador, com a proposição de uma metodologia participativa para elaboração do documento, por meio de instrumentos democráticos como as assembleias locais e a assembleia geral.

Um outro fator relevante a ser analisado nesse processo é a questão da autonomia institucional, conforme explica Veiga (1998) :

\begin{abstract}
Para ser autônoma, a escola não pode depender somente dos órgãos centrais e intermediários que definem a política da qual ela não passa de executora. Ela concebe sua proposta pedagógica ou projeto pedagógico e tem autonomia para executá-lo e avaliá-lo ao assumir uma nova atitude de liderança, no sentido de refletir sobre as finalidades sociopolíticas e culturais da escola (VEIGA, 1998, p. 15).
\end{abstract}

Um aspecto importante a ser tratado sobre essa relativa autonomia pedagógica institucional foi reconhecer que os documentos oficiais das políticas públicas em educação, nos dizeres de Fairclough (2001), os documentos oficiais das políticas públicas em educação expressam disputas de discursos posto que explicitam argumentos discordantes. Com referência no modelo de análise de política educacional proposto por Bowe e Ball (1992), pode-se interpretar que os argumentos em disputa influenciam o processo de construção do PPI do IFSC, já que a formulação desses documentos de referência deu-se no chamado contexto de produção de textos, que incluem documentos oficiais que representam a política. Por sua vez, esses documentos oficiais sofreram influências de discursos da política que foram formulados no chamado contexto de influência, no qual partes interessadas disputam a definição e propósitos sociais da educação. Nesse sentido, o processo de formulação do PPI do IFSC, situa-se no chamado contexto da produção de textos, ainda sob o impacto do contexto de influência, e aproximando-se do chamado contexto das práticas, onde os educadores são influenciados pelos discursos da política, porém, com possibilidade de leitura diferenciada dos mesmos .

Sobre a disputa pela definição e propósitos sociais da educação, que ocorre no âmbito macro de formulação das políticas públicas, influenciando a educação em geral e a educação profissional, em particular, conforme nos diz Araújo e Rodrigues (2010, p. 51), identifica-se "campos de disputa em que predominam abordagens de dois tipos: aquelas que buscam a conformação dos homens à realidade dada e outras que buscam a transformação social".

Para tanto, na terceira seção desse artigo analisou-se as contradições internas à formulação do PPI, necessitando de um esforço investigativo para identificar os elementos contraditórios do discurso textual, manifestada por meio da disputa de distintas concepções de projetos societários, que ocorrem no âmbito mais amplo das políticas públicas educacionais, entre o conformismo e a perspectiva de mudança estrutural da ordem social. Além disso, também 
atentou-se à observação das ausências de elementos do discurso textual para elucidação da concepção educativa anunciada pelo documento.

\section{OS PRESSUPOSTOS TEÓRICOS DA PEDAGOGIA HISTÓRICO-CRÍTICA}

$\mathrm{Na}$ assembleia do PPI do IFSC, conforme registro de ata sobre as discussões e deliberações de propostas, observou-se uma disputa entre a concepção de educação progressista, da minuta do documento, e a concepção de educação histórico-crítica, do documento base (IFSC, 2013).

Considerando as argumentações dos defensores de cada proposta, destaca-se que a primeira, progressista, foi defendida por sua conotação mais abrangente em relação a segunda proposta, sem necessariamente negá-la. Sobre a segunda, não houve uma defesa clara em termos dos seus pressupostos teóricos, mas pode-se situá-la como uma corrente pedagógica no Brasil, de caráter crítico, tendo como pressuposto filosófico o materialismo histórico dialético e que almeja mudanças estruturais na sociedade na perspectiva dos trabalhadores. A segunda concepção teve maior votação, por amostragem, com a inclusão a essa proposta de um parágrafo abordando a educação como um fenômeno social.

Acredita-se que o PPI do IFSC, por meio da sua concepção educativa, deva explicitar os seus fundamentos, de forma a garantir o mesmo referencial conceitual para elaboração das propostas formativas. Os trechos a seguir mostram a presença da pedagogia histórico-crítica no PPI do IFSC:

A proposta de EPT do IFSC sustenta-se em uma concepção de educação integral do sujeito, cujo caráter é de totalidade, possibilitando a manifestação das individualidades, sem limitar-se apenas ao trabalho manual ou intelectual da atividade produtiva (SILVEIRA, 2007). Entende-se que o trabalho como princípio educativo geral "se encaminha na direção da superação entre trabalho manual e trabalho intelectual, entre instrução profissional e instrução geral" (SAVIANI, 1989, p.13), sem separar o conhecimento teórico do conhecimento prático, voltando-se para a formação do homem integral, sem a preocupação de apenas prepará-lo para o mercado de trabalho. Nessa concepção, a indissociabilidade entre ensino, pesquisa e extensão precisa ser garantida (IFSC, 2014, p. 2.5).

Ao levar em conta a realidade do aluno, é preciso favorecer a transformação para outra realidade, que represente igualdade de condições de acesso ao conhecimento e satisfação das necessidades do ser humano. Essas necessidades servem como referência para a compreensão da ciência, da tecnologia e da educação como atividades que precisam ser elaboradas em favor do desenvolvimento humano (IFSC, 2014, p. 2.11). 
Mas afinal, como se situa a concepção histórico-crítica no contexto das correntes pedagógicas no Brasil? Como e por quais razões essa concepção educativa surgiu? Quais são os seus pressupostos teóricos? Quais são os seus principais desafios e como essa corrente pedagógica vem sendo desenvolvida?

Sobre a origem da Pedagogia Histórico-Crítica, no contexto das correntes pedagógicas do Brasil, ao final dos anos setenta do século passado, deve-se compreendê-la principalmente como uma proposta de superação do modelo educacional tecnicista, adotado pelo regime político civil-militar.

\begin{abstract}
A pedagogia histórico-crítica surge como corrente educacional em 1979, quando o problema de abordar dialeticamente a educação começou a ser discutido mais ampla e coletivamente. Naquele momento, se procurava superar tanto as teorias crítico-reprodutivistas, presentes no pensamento de Althusser, Bourdieu e Passeron e Baudelot e Establet (teoria da escola como violência simbólica, como aparelho ideológico de Estado, e teoria da escola dualista), quanto as teorias não críticas (pedagogia tradicional, pedagogia nova e pedagogia tecnicista). Saviani traduz com a expressão "pedagogia histórico-crítica" o empenho em compreender a questão educacional com base no desenvolvimento histórico objetivo (RAMOS, 2010, p. 225-226).
\end{abstract}

Naquele momento, as teorias crítico-reprodutivistas (teoria da escola como violência simbólica, como aparelho ideológico de Estado, e teoria da escola dualista) ajudaram a denunciar a escola como um aparelho de reprodução das desigualdades sociais, a serviço dos interesses dos grupos dominantes.

[...] A escola teria, assim, um papel ativo - ao definir seu currículo, seus métodos de ensino e suas formas de avaliação - no processo social de reprodução das desigualdades sociais. Mais do que isso, ela cumpriria o papel fundamental de legitimação dessas desigualdades, ao dissimular as bases sociais destas, convertendo-as em diferenças acadêmicas e cognitivas, relacionadas aos méritos e dons individuais (NOGUEIRA; NOGUEIRA, 2002, p. 18-19).

No Brasil, as teorias crítico-reprodutivistas sobre o papel da escola serviram para denunciar o modelo vigente, porém, não apresentaram uma alternativa para superá-lo. Nesse sentido, a Pedagogia Histórico-Crítica surge para suprir essa necessidade. Sobre os pressupostos teóricos dessa pedagogia, segundo Saviani (2011, p. 80), "são os da concepção dialética da história". De forma mais explícita sobre as suas bases teóricas, o autor explica:

Quanto às bases teóricas da pedagogia histórico-crítica, é óbvio que a contribuição de Marx é fundamental. Quando 
se pensam os fundamentos teóricos, observa-se que, de um lado, está a questão da dialética, essa relação do movimento e das transformações; e, de outro, que não se trata de uma dialética idealista, uma dialética entre os conceitos, mas de uma dialética do movimento real. Portanto, trata-se de uma dialética histórica expressa no materialismo histórico, que é justamente a concepção que procura compreender e explicar o todo desse processo, abrangendo desde a forma como são produzidas as relações sociais e suas condições de existência até a inserção da educação nesse processo. (SAVIANI, 2011, p. 119-120).

Analisando a contextualização teórica da Pedagogia Histórico-Crítica, elaborada por Saviani (2011), e tendo como referência a concepção dialética histórica, expressa no materialismo-histórico, para uma melhor compreensão das bases conceituais dessa corrente pedagógica, destaca-se os sentidos da práxis, da mediação e da totalidade. Sobre o significado de práxis, Saviani (2011, p. 120) entende "como uma prática fundamentada teoricamente". Nessa relação, da prática com a teoria, no sentido da práxis, explicita-se o movimento do conhecimento como a passagem do "empírico ao concreto". Nesse movimento, da passagem da síncrese à síntese, pela mediação da análise, passa-se de um estado "mais ou menos caótico", para um estado onde tem-se "a visão do todo com a consciência e a clareza das partes que o constituem".

Portanto, a partir dos pressupostos teóricos acima apresentados, aplica-se o método da Pedagogia Histórico-Crítica, com as seguintes etapas: prática social, problematização, instrumentalização, catarse e prática social, assim explicado por Ramos (2010) .

O autor propõe o método histórico-crítico de educação, baseado na contínua vinculação entre educação e sociedade. Suas etapas são as seguintes: a) prática social (comum a professores e alunos). Professores e alunos podem se posicionar como agentes sociais diferenciados. Eles também se encontram em níveis diferentes de compreensão (conhecimento e experiência) da prática social; b) problematização (identificação dos principais problemas da prática social). Trata-se de detectar que questões precisam ser resolvidas no âmbito da prática social e, em consequência, que conhecimentos são necessários dominar; c) instrumentalização (apropriação dos instrumentos teóricos e práticos indispensáveis ao equacionamento dos problemas detectados na prática social). Tais instrumentos são produzidos socialmente e preservados historicamente. A sua apropriação pelos alunos está na dependência da transmissão direta ou indireta por parte do professor; d) catarse (efetiva incorporação dos instrumentos culturais, modificados para elementos ativos de transformação social); e e) prática social (RAMOS, 2010, p. 231). 
No entendimento de Saviani (2011), um dos desafios para o desenvolvimento da Pedagogia Histórico-Crítica refere-se à problemática que envolve a prática, com destaque para: a) ausência de um sistema de educação; b) a necessidade de uma mudança na organização objetiva da realidade, para que se viabilize a nova teoria nas condições práticas; c) a descontinuidade das práticas em razão das mudanças políticas.

Considerando o PPI do IFSC, aprovado pela assembleia, constatou-se que os pressupostos teóricos e bases conceituais da Pedagogia HistóricoCrítica, aqui mencionados, não foram suficientemente apresentados no documento. Durante a assembleia houve proposições para explicitar a concepção histórico-crítica, mas em razão da metodologia adotada, a mesa diretora indeferiu a apreciação das mesmas. Quais são as consequências dessas ausências no documento final, referentes aos sentidos da concepção histórico-crítica, para construção da identidade institucional?

\section{A CONCEPÇÃO DO ENSINO MÉDIO INTEGRADO}

Mas afinal, haveria uma oferta educativa mais adequada se formos pensar num projeto educativo condizente com os pressupostos da concepção histórico-crítica? Ao apresentar o projeto educativo do Ensino Médio Integrado, com o seu significado mais amplo, como um horizonte de um ensino médio de qualidade para todos, identificamos nesse projeto uma referência para efetivação dos pressupostos teóricos presentes na concepção histórico-crítica. Conforme os dizeres de Simões (2010, p. 117):

[...] acreditamos numa escola que não se limite ao interesse imediato, pragmático e utilitário. Uma formação com base unitária, no sentido de um método de pensar e de compreender as determinações da vida social e produtiva - que articula trabalho, ciência e cultura na perspectiva da emancipação humana. Nesse sentido, reconhecemos o ensino médio integrado, com seu significado mais amplo, o horizonte de um ensino médio de qualidade para todos e no qual a articulação com a educação profissional técnica de nível médio constitui uma das possibilidades de garantir o direito à educação e ao trabalho qualificado (SIMÕES, 2010, p. 117).

O próprio autor da pedagogia histórico-crítica, Dermeval Saviani, reconheceu o Ensino Médio Integrado como um projeto educativo de referência para construção de uma escola unitária.

O ensino médio integrado ao ensino técnico, conquanto seja uma condição social e historicamente necessária para construção do ensino médio unitário e politécnico, não se confunde totalmente com ele porque a conjuntura do real assim 
não o permite. Não obstante, por conter os elementos de uma educação politécnica, contém também os germens de sua construção (1997, apud RAMOS, 2008, p. 12).

Sobre os pressupostos filosóficos que fundamentam a organização curricular dessa perspectiva de integração do Ensino Médio com a Educação Profissional (EMI), de acordo Ramos (2008), destacam-se dois pressupostos: 1ํ) A concepção de homem como ser histórico-social que age sobre a natureza para satisfazer suas necessidades e, nessa ação produz conhecimentos como síntese da transformação da natureza e de si próprio; $2^{\circ}$ ) A realidade concreta é uma totalidade, síntese de múltiplas relações.

Desses pressupostos derivam os sentidos da integração do Ensino Médio à Educação Profissional , que, nos dizeres de Ramos (2008), são: a) O primeiro sentido da integração é o da formação omnilateral. $O$ conceito de trabalho como "a primeira mediação entre o homem e a realidade material e social". A integração do trabalho, da ciência e da cultura, como dimensões fundamentais da vida que estruturam a prática social, na perspectiva da formação omnilateral dos sujeitos. b) O segundo sentido da integração é o da indissociabilidade entre educação profissional e educação básica. $O$ reconhecimento que, de forma singular para as classes trabalhadoras, o direito ao trabalho na sua perspectiva econômica configura a profissionalização dos jovens como uma necessidade. $O$ entendimento que o ensino médio integrado ao ensino técnico seja construído sob uma base unitária de formação geral, sendo essa uma condição necessária para se fazer a "travessia" para uma nova realidade (FRIGOTTO, 2005). c) O terceiro sentido da integração é o da integração de conhecimentos gerais e específicos como totalidade. Considerando que todo fenômeno/prática social possui as dimensões físicoambiental, econômica-produtiva, técnico-organizacional, sócio-históricacultural. A compreensão do real como totalidade exige que se conheçam as partes $e$ as relações entre elas, o que nos leva a constituir seções tematizadas da realidade (RAMOS, 2008).

Conforme exposto acima, as bases conceituais da Pedagogia Histórico-Crítica (práxis, mediação e totalidade), manifestam-se claramente no projeto do EMI. A práxis no sentido da integração de conhecimentos gerais e específicos e da indissociabilidade entre a educação profissional e a educação básica. A mediação no sentido do trabalho como princípio educativo para integrar as dimensões da prática social (trabalho, ciência e cultura), para uma formação omnilateral dos sujeitos. A totalidade nos diversos sentidos do projeto do EMl.

Dada a concepção histórico-crítica, aprovada em assembleia pela comunidade acadêmica, e aquilo que defendemos como projeto educativo coerente com os seus pressupostos, será que a instituição conseguiu direcionar os seus esforços no sentido de fortalecer a implementação do Ensino Médio Integrado para o período de vigência do PPI? 


\section{METODOLOGIA}

Para os fins metodológicos do artigo utiliza-se o método materialista histórico dialético. Nos dizeres de Konder (2008), esse método investiga e analisa o fenômeno, observando os elementos que o integram e estabelece relações sociais e históricas; procura caracterizar os aspectos fundamentais do fenômeno, sua realidade concreta, por intermédio de estudos das informações e observações; faz uso de descrição, classificação, análise das contradições do fenômeno e síntese do observado e analisado.

A realidade investigada apresenta-se como uma "cortina de fumaça" que atua de forma a dificultar a compreensão do objeto da pesquisa. Nesse sentido, o uso do método materialista histórico dialético torna-se imprescindível para construção do conhecimento científico e social acerca do objeto de pesquisa analisado. Sobre isso, explica Rodríguez (2014):

O método materialista histórico, para análise do real, parte dos dados empíricos que se apresentam de forma global e difusa, para logo realizar uma desagregação dos dados e estabelecer diferentes relações, que permitem fazer uma interconexão que possibilita verificar as múltiplas determinações que se estabelecem entre os dados singulares com 0 universal (RODRÍGUEZ, 2014, p. 146).

Destaca-se a importância do método materialista histórico dialético para interpretação da linguagem, entendida como um elemento que atua de forma a ocultar a verdade, distorcendo a realidade para promover a manutenção das relações de poder, em prol dos interesses de uma classe dominante. Sobre isso, explica Rodríguez (2014):

O método materialista histórico dialético permite evidenciar esse processo, no qual a linguagem atua como um elemento catalisador do poder e se torna um agente que desloca a realidade, dando um conteúdo ideológico que oculta a verdade, excluindo a história e o conhecimento científico. O discurso atua como factótum totalizador que distorce a realidade para promover a verdade da classe dominante (RODRÍGUEZ, 2014, p. 135).

Como opção metodológica do método materialista histórico-dialético, enquanto estratégia de aproximação do objeto de estudo, definiu-se algumas unidades de análise em tensão, em particular a categoria metodológica da contradição.

Para fins de análise, selecionou-se os PPCs Técnicos Integrados do IFSC, de 2015 a 2018. Com referência na categoria metodológica da contradição, esses documentos foram analisados com 0 intuito de compreender a materialidade do discurso textual, tendo em vista a concepção 
educativa proclamada no PPI do IFSC. A contradição aqui entendida como a relação/conexão entre partes diferentes de uma totalidade que constitui-se como unidade dos contrários, tornando-se essenciais para compreensão de determinados aspectos da realidade humana (KONDER, 2008).

Uma das hipóteses levantadas para essa análise inicial trata das contradições mais amplas da nossa sociedade capitalista, em particular a principal delas, entre capital e trabalho, que manifesta-se mediante o discurso e a linguagem, na sua forma textual, e se reproduz no espaço institucional. Sobre isso, Rodríguez (2014, p. 135) diz que a análise inicial do método materialista histórico dialético serve para "identificar como a verdade hegemônica e totalitária imposta pela classe dominante, mediante o discurso e a linguagem, se reproduz nos espaços institucionais formais, como a escola".

\section{RESULTADOS E DISCUSSÕES: ENTRE O PROCLAMADO E 0 REALIZADO}

No presente tópico do artigo, a partir da concepção de educação histórico-crítica, democrática e emancipadora que foi proclamada no PPI do IFSC, analisou-se aquilo que foi realizado em termos de coerência, contradição e ausência do discurso textual. Para essa análise, no âmbito do IFSC, utilizouse o documento do PPI, aprovado em assembleia, os Projetos Pedagógicos dos Cursos (PPCs) Técnicos de Nível Médio, na forma integrada, entre os anos de 2015 e 2018, assim como as orientações da Pró-Reitoria de Ensino para elaboração dos pareceres dos conselheiros do Colegiado de Ensino, Pesquisa e Extensão (CEPE) sobre as propostas de reestruturação e criação de PPCs.

Porém, não podemos analisar os documentos oficiais locais, no âmbito do IFSC, em desarticulação com os documentos oficiais das políticas públicas educacionais. Como já explicitado em tópico anterior, os documentos oficiais das políticas públicas educacionais manifestam a disputa de distintas concepções de projetos societários, entre o conformismo e a perspectiva de mudança estrutural à ordem social, por meio de elementos contraditórios em termos do discurso textual. Portanto, nossa análise do PPI, foi realizada na interlocução imprescindível com os documentos oficiais das politicas públicas educacionais, particularmente no âmbito da EPT, na tentativa de identificar sua(s) influência(s) sobre o processo de elaboração do documento, dada por intermédio dos sujeitos que participam do processo, assim como das determinações legais que impactaram na relativa autonomia pedagógica institucional.

No capítulo 2.1 do PPI do IFSC, intitulado de Concepção de Educação, proclamou-se a concepção de educação da instituição como "histórico-crítica, democrática e emancipadora" (IFSC, 2013, p. 8). Para fins de análise do PPI no contexto das políticas públicas, destaca-se a coerência entre o Decreto n.. 5.154/2004 e a concepção de educação do PPI do IFSC, ao menos em termos do discurso proclamado nos textos.

Para além da constatação da confluência em termos de concepção educativa, entre o Decreto n. $\stackrel{0}{5.154 / 2004}$ e o PPI do IFSC, conforme exposto 
acima, entre os textos das políticas públicas, a nossa análise não deve prescindir em observar as possíveis inconsistências e/ou contradições que também estão presentes.

Uma dessas inconsistências do $\mathrm{PPI}$, em relação a sua concepção educativa histórico-crítica, refere-se ao fato que o documento não apresenta esclarecimentos sobre os pressupostos teóricos e de suas bases conceituais. Ao constatarmos aquilo que o documento também "não diz", faz-se a seguinte indagação: a ausência de esclarecimentos sobre os pressupostos da concepção educativa ocorre, em razão de um ato consciente daqueles que discordam da concepção, ou trata-se de uma incapacidade argumentativa daqueles que a defenderam?.

\begin{abstract}
O estudo aprofundado sobre que conceitos e argumentos são privilegiados e quais os intencionalmente "desprezados" nos aproxima da lógica ou racionalidade que sustenta os documentos. Essa tarefa exige um olhar investigativo sobre os textos oficiais - legislação, relatório, documento - para ler o que dizem, mas também para captar o que "não dizem" (CAMPOS; GARCIA; SHIROMA, 2005, p. 439)
\end{abstract}

O PPI do IFSC, também em relação a sua concepção educativa, apresenta uma contradição conceitual quando proclama sua proposta curricular interdisciplinar para o desenvolvimento de competências.

Em consonância com os objetivos de inclusão e emancipação no ideário de educação do IFSC, apontamos como proposta um currículo interdisciplinar, que atende ao desenvolvimento das competências traçadas a partir de situações concretas das diferentes áreas profissionais, visando a promover a socialização dos saberes, superar a fragmentação entre as diferentes áreas do conhecimento e perceber o aluno como uma totalidade. (IFSC, 2014)

A hegemonia de tendências educacionais pragmáticas, compreendida como coerção revestida de consenso (GRAMSCl, 2002) que dá direção cultural e material a um grupo social (RAMOS, 2017), expressa-se nos dias de hoje por meio da pedagogia das competências. A sua gênese no contexto local, dentre outras razões a serem investigadas, pode ser explicada pela implantação das novas diretrizes curriculares que ocorreram na década de 1990, no processo da Reforma Educacional da EPT. A dissertação elaborada por Coelho (2012), retoma a gênese dessa mudança de paradigma curricular no IFSC. As consequências desse processo de profundas transformações na identidade institucional, também foram apontadas por Guedes (2016). As autoras desses trabalhos acadêmicos são servidoras lotadas na Coordenadoria Pedagógica, do câmpus Florianópolis, e estão diretamente envolvidas com 0 processo de trabalho para elaboração de pareceres sobre PPCs. 
Na chamada era das diretrizes, conforme nos explica Ramos e Ciavatta (2012), a chamada pedagogia das competências, sob forte influência de organismos internacionais, influenciou a elaboração das diretrizes curriculares nacionais, em particular as Diretrizes Curriculares Nacional para Educação Profissional Técnica de Nível Médio (DCNEP). Por sua vez, sob a orientação da conformidade necessária em relação aos documentos oficiais das políticas públicas, essa diretriz curricular influenciou a elaboração do PPI, corroborando para o acirramento das contradições internas ao documento.

Essas inconsistências e contradições internas ao documento, conforme destacamos na formulação do PPI do IFSC, de certa maneira, refletem as disputas ideológicas que se dão no âmbito macro das políticas públicas educacionais, em particular no campo da EPT. Considerando o contexto de influência explicado por Bowe e Ball (1992), no processo de elaboração das DCNEP, observamos a disputa de grupos com concepções societárias distintas, no interior da comissão especial do Conselho Nacional de Educação, responsável pela elaboração dessas diretrizes. Para exemplificar essa constatação, no tópico das DCNEP (2012, p. 06), intitulado "O mundo do trabalho como referência para a Educação Profissional”, diz que:

\begin{abstract}
Espera-se que o mundo do trabalho avance na direção de relações trabalhistas mais justas. Isso implica numa maior participação dos trabalhadores nos destinos e nos processos de trabalho. Para que isso aconteça é necessário que o trabalhador tenha conhecimento da tecnologia, da ciência e dos processos necessários em sua produção. (BRASIL, 2012)
\end{abstract}

Esse trecho, acima mencionado, expressa a ideia de responsabilização do indivíduo pelo seu fracasso, simplificando a problemática das relações trabalhistas. Essa crença é condizente com uma visão de mundo meritocrática, sob influência da Teoria do Capital Humano, que nos dizeres de Frigotto (2015, p. 209), "buscam mascarar o que está subjacente". Contraditoriamente a essa concepção, em outro trecho do mesmo tópico das DCNEP, observa-se a expressão de uma concepção epistemológica fundamentada no materialismo histórico.

[...] objetivando a sua formação integral, ou seja, que consiga superar a dicotomia historicamente cristalizada da divisão social do trabalho entre a ação de executar e as ações de pensar, planejar, dirigir, supervisionar ou controlar a qualidade dos produtos e serviços ( BRASIL, 2012, p. 06)

Como vimos, essas expressões contraditórias exemplificam a presença de vozes discordantes nos seus diferentes contextos de formulação das políticas públicas. No âmbito local do IFSC, na tentativa de compreender os desdobramentos dessas contradições, em termos de discurso textual, presentes no documento do PPI, analisou-se os Projetos de Cursos Técnicos de Nível Médio, na sua forma integrada. Tendo como referência o período de 
vigência do atual PDI do IFSC, conforme o quadro abaixo, analisou-se um total de vinte e dois Projetos de Cursos Técnicos de Nível Médio, na forma integrada, que foram submetidos ao CEPE, no período de 2015 a 2018, sendo dezesseis projetos para criação e seis projetos para alteração.

Quadro 1: Projetos do Curso Técnico Integrado do IFSC, criados e reestruturados entre 2015 e 2018

\begin{tabular}{|c|c|}
\hline NOME DO PPC & RESOLUÇÃO/CEPE \\
\hline Química/Criciúma & N. $10 / 2015$ (criação) \\
\hline Administração/Caçador & N. ㅇ 24/2015 (criação) \\
\hline Agropecuária/São Miguel do Oeste & N. ㅇ 31/2015 (criação) \\
\hline Alimentos/Xanxerê & $\begin{array}{l}\mathrm{N} . .931 / 2015 \text { (criação) } \\
\text { (revogada pela } \mathrm{N} . \mathrm{0} \text { 144/2017) }\end{array}$ \\
\hline Informática/Caçador & $\begin{array}{l}\mathrm{N} . .942 / 2015 \text { (criação) } \\
\text { (revogada pela N.․ 24/2017) }\end{array}$ \\
\hline Informática/Xanxerê & N. 42/2015 (criação) \\
\hline Alimentos/Canoinhas & N.ㅇ 49/2015 (criação) \\
\hline Edificações/Canoinhas & N. 57/2015 (criação) \\
\hline Eletromecânica/São Miguel do Oeste & N.o 08/2016 (criação) \\
\hline Recursos Pesqueiros/Itajaí & N.ㅇ 27/2016 (criação) \\
\hline Alimentos/São Miguel do Oeste & N.ㅇ 61/2016 (criação) \\
\hline Plásticos/Caçador & N.․ 108/2017 (criação) \\
\hline Agroecologia/Canoinhas & N.․ 130/2017 (criação) \\
\hline Modelagem/Jaraguá do Sul & N. 111/2017 (criação) \\
\hline Mecânica/Xanxerê & N. 107/2017 (criação) \\
\hline Informática/Xanxerê & N.ㅇ 04/2018 (criação) \\
\hline $\begin{array}{l}\text { Tradução e Interpretação de Libras- } \\
\text { Português/Palhoça-Bilíngue }\end{array}$ & N.ำ 182/2017 (alteração) \\
\hline $\begin{array}{lll}\text { Bilíngue } & \text { Comunicação } \quad \text { Visual/Palhoça }\end{array}$ & N.․ 154/2017 (alteração) \\
\hline Química/Jaraguá do Sul & N. 117/2017 (alteração) \\
\hline Química/Gaspar & N.ㅇ 021/2018 (alteração) \\
\hline Informática/Gaspar & N.ㅇ 020/2018 (alteração) \\
\hline Comunicação Visual/Palhoça Bilíngue & N. 01/2018 (alteração) \\
\hline
\end{tabular}

Fonte: Próprio autor

A análise dos PPCs dos Cursos Técnicos Integrados do IFSC, criados ou reestruturados de 2015 a 2018, baseou-se na pesquisa de termos relacionados a concepção educativa histórico-crítica, tais como: Projeto Pedagógico Institucional, PPI, concepção de educação, histórico-crítica, dialética, materialismo histórico, práxis, mediação e totalidade. $\mathrm{O}$ resultado dessa pesquisa foi a não constatação, na ampla maioria dos PPCs analisados 
(88\% dos casos), de nenhum tipo de menção aos referidos termos. No restante dos casos (12\%), foram mencionados termos que sugerem alguma relação à concepção educativa do IFSC. Apesar dessa constatação, não ignora-se a possibilidade de outros elementos textuais dos PPCs, mesmo não relacionados diretamente aos termos pesquisados, possam ter sido previstos com referência nos pressupostos e bases conceituais da concepção histórico-crítica. Assim como, das práticas educativas dos professores que atuam nesses projetos também serem coerentes com a concepção educativa do IFSC. Essas seriam hipóteses para serem confirmadas ou refutadas noutro trabalho de pesquisa.

Apesar da decisão da comunidade acadêmica, aprovada pela assembleia geral, optando pela concepção educativa histórico-crítica, o que predominou em termos de esforço institucional, de 2015 a 2018, foi a perspectiva operacional pragmática, materializada por meio de um conjunto de instrumentos e aparatos de orientação que, desde então, acabaram se efetivando na grande maioria dos projetos de cursos. Afinal, quais os critérios institucionais utilizados pelos sujeitos que elaboram esses projetos, assim como para aqueles que avaliam a aprovação dos mesmos, nos colegiados de câmpus e CEPE? Para tentar responder a esse questionamento, identificou-se no endereço eletrônico do CEPE, um check list para uso dos parecistas (IFSC, 2018). Dentre os critérios sugeridos nesse documento, não há nenhuma menção à concepção de educação do IFSC. Em relatório de inconsistências frequentes na criação/alteração de PPCs do IFSC (IFSC, 2018), documento enviado, via e-mail institucional, pela Diretoria de Ensino da Reitoria em 15/03/2018, também não houve nenhuma menção à concepção educativa do IFSC. Esse estudo sobre as inconsistências dos PPCs foi disponibilizado aos servidores, professores e técnico-administrativos, que atuam nos processos de elaboração e avaliação de projetos de cursos.

$\mathrm{Na}$ análise dos PPCS, também foram pesquisados os termos relacionados a proposta curricular para o desenvolvimento das competências, tais como: competência(s), conhecimento(s), habilidade(s), atitude(s). Do total de vinte e dois projetos analisados, dezenove (86\%) tiveram o planejamento dos componentes curriculares organizados pelo ensino de competências. Essa constatação indica a continuidade de uma tendência dos PPCs, referente à oferta do ensino médio integrado no IFSC, anterior ao PDI do IFSC vigente, de agosto de 2014 a julho de 2015, corroborando com os resultados do trabalho de pesquisa desenvolvido pelo Grupo de Estudo e Pesquisa em Currículo Integrado do Instituto Federal de Santa Catarina, câmpus Chapecó-SC, afirmando que "[...] os PPCs deixam claro em suas linhas que o ensino visa prioritariamente às competências e habilidades necessárias ao emprego, e não a uma formação crítica e cidadã" (AGNE et al, 2019, p. 96).

Percebe-se, portanto, que a materialização dos projetos dos Cursos Técnicos de Nível Médio, na sua forma integrada, no IFSC, dialoga pouco ou quase nada com os pressupostos teóricos e bases conceituais da sua concepção educativa, conforme proclamada no seu PPI. Na análise dos vinte e dois projetos de cursos, observou-se que um total de dezoito projetos foram escritos seguindo a diretriz operacional da pedagogia das competências, no detalhamento dos seus componentes curriculares. 
$\mathrm{Na}$ tentativa de compreender esse distanciamento, entre o proclamado e o realizado, identificou-se orientações institucionais com foco na conformidade dos PPCs aos aspectos normativos internos e da legislação educacional específica. Em contrapartida, a concepção educativa do PPI do IFSC não tem sido referência para os trabalhos de análise e pareceres desses PPCs, que são elaborados por servidores lotados nas Coordenadorias Pedagógicas dos câmpus e servidores eleitos para o Colegiado de Ensino, Pesquisa e Extensão (CEPE).

Por fim, todas essas contradições, inconsistências e ausências, entre o proclamado e o realizado, dificultam o fortalecimento de uma oferta educativa coerente com concepção educativa assumida na assembleia do PPI, em 2013, e consequentemente, impactam o processo de consolidação da identidade institucional.

O fato de não ter havido uma indução institucional dos cursos integrados e a busca de coerência com a concepção do PPI não significa que nenhuma concepção orientou o processo cotidiano da instituição.

A presença de elementos pragmáticos nos documentos analisados deixam claro que outros instrumentos institucionais deram prioridade à diretriz operacional, por competências, presente de maneira paradoxal no PPI. Para compreender as raízes da perspectiva hegemônica da pedagogia das competências na materialização das propostas formativas, particularmente no âmbito do IFSC, faz-se necessária a retomada dos marcos políticos da reforma da educação profissional ocorrida, no Brasil, na segunda metade da década de noventa, do século passado. Desde então, há fortes evidências que tem prevalecido a materialização da perspectiva das competências, não na sua forma "pura", mas naquilo que poderíamos denominar, segundo Ramos (2010), como sendo uma síntese epistemológica pragmática, com elementos da pedagogia escolanovista permeada por elementos da pedagogia libertadora e atualizada pela pedagogia das competências.

\section{CONSIDERAÇÕES FINAIS}

$\mathrm{Na}$ tentativa de compreender os limites, desafios e possibilidades, diante da Reforma do Ensino Médio, esse artigo retomou a concepção de educação proclamada no Projeto Pedagógico Institucional do IFSC, numa análise ampliada que considerou o processo de elaboração do documento, os limites da autonomia pedagógica da instituição, o envolvimento dos sujeitos que participaram da sua construção, a influência dos documentos oficiais das politicas públicas e o aprofundamento dos pressupostos e bases conceituais da sua proposta educativa.

O projeto educativo do EMI, construído na perspectiva de formação integral das diversas dimensões da prática social - trabalho, ciência e cultural é inteiramente coerente com a concepção educativa histórico-crítica, proclamada no PPI do IFSC, pois possui os mesmos pressupostos teóricos, com referência no materialismo histórico dialético, assim como as bases conceituais da práxis, da mediação e da totalidade. Nesse sentido, diante da 
atual Reforma do Ensino Médio, deve-se resistir na defesa dos pressupostos teóricos e bases conceituais da concepção educativa do IFSC.

A construção dessa resistência apresenta desafios institucionais. $O$ primeiro deles é a necessidade dos PPCs serem construídos e avaliados de forma a respeitar a concepção de educação proclamada no PPI do IFSC. As fortes evidências, conforme constatamos na nossa análise, de que a pedagogia das competências prevalece sobre a concepção educativa histórico-crítica, evidencia o distanciamento que existe entre o proclamado na concepção educativa do PPI do IFSC e o realizado nos projetos de curso.

Para tanto, diferentes ações institucionais, de formação e informação, devem ser realizadas, no sentido de fomentar a compreensão sobre os pressupostos teóricos e bases da concepção educativa institucional. Sobre isso, tem-se observado no IFSC, desde 2015, o fortalecimento operacional dos processos de criação e reestruturação dos projetos de cursos, com destaque para harmonização curricular em termos dos seus aspectos normativos e de legislação. Em contrapartida, demonstra-se fortes evidências que a concepção educativa proclamada no PPI do IFSC não tem sido utilizada como referência para nenhuma iniciativa de formação continuada para os servidores que atuam diretamente nos processos e criação e reestruturação dos projetos de cursos. Tampouco, pelas fontes pesquisadas até o momento, a concepção educativa do PPI do IFSC explicita-se como critério avaliativo para os trabalhos de análise e pareceres desses projetos, que são desenvolvidos por servidores das Coordenadorias Pedagógicas e pelos conselheiros do CEPE.

A não realização de iniciativas que fortaleçam a construção de uma identidade institucional, coerente com a concepção educativa proclamada no PPI do IFSC, revela evidências de uma outra concepção educativa, com base epistemológica pragmática, que está orientando as ações institucionais. Provavelmente, essa constatação explique a demora institucional para definição de um posicionamento frente a atual reforma do ensino médio, mesmo que os pressupostos e bases conceituais da concepção educativa histórico-crítica sejam suficientes para justificar um posicionamento de resistência.

A conjuntura atual é desfavorável para os projetos de caráter progressista, como é o caso do projeto educativo do EMI. Mas como diria Antônio Gramsci (1982):

É necessário criar homens sóbrios, pacientes, que não se desesperem diante dos piores horrores e que não se exaltem em face de qualquer tolice. Pessimismo da inteligência, otimismo da vontade. (GRAMSCI, 1982, p. 222-223).

Trata-se, portanto, de seguir na luta, tendo clareza dos desafios e também sempre perseguindo a utopia de uma formação mais ampliada possível. Nesse sentido, parafraseando Ramos (2008), deve-se assumir a posição daqueles que contribuem para construção de uma sociedade justa e integradora, que inclui, que reconhece a diversidade, que valoriza os sujeitos e a sua capacidade de produção da vida, assegurando direitos sociais plenos. 


\section{REFERÊNCIAS}

AGNE, Sandra Aparecida Antonini; BENINCÁ, Erica Mastela; DE CARVALHO, Margarete Gonçalves Macedo; GREGGIO, Saionara; POSSAMAI, Leusa Fátima Lucateli. In: SOUZA, Francisco das Chagas Silva; NUNES, Albino Oliveira (orgs.). Temas em educação profissional e tecnológica / Francisco das Chagas Silva Souza e Albino Oliveira Nunes (organizadores). - Campos dos Goytacazes, RJ: Essentia, 2019.

ARAÚJO, R. M. L.; RODRIGUES, D. S. Referências sobre práticas formativas em Educação Profissional: o velho travestido de novo ante o efetivamente novo. Boletim Técnico do Senac, Rio de Janeiro, v.36, n.2, maio/ago. 2010. Disponível em:

http://www.senac.br/bts/362/ar;go4.pdf . Acesso em 10 nov. 2017

BOWE, R.; BALL, S. Reforming education and changing schools: case studies in policy sociology. London: Routledge, 1992.

BRASIL. Decreto 으. 5.154/2004. Regulamenta o $\S 2^{\circ}$ do art. 36 e os arts. 39 a 41 da Lei no 9.394, de 20 de dezembro de 1996, que estabelece as diretrizes e bases da educação nacional, e dá outras providências. Disponível em: http://www.planalto.gov.br/ccivil_03/_ato2004-2006/2004/decreto/d5154.htm. Acesso em 10 nov. 2017.

BRASIL. Lei n.- 11.892/2008. Institui a Rede Federal de Educação Profissional, Científica e Tecnológica, cria os Institutos Federais de Educação, Ciência e Tecnologia, e dá outras providências. Disponível em:

http://www.planalto.gov.br/ccivil_03/_ato2007-2010/2008/lei//11892.htm. Acesso em 10 nov. 2017.

BRASIL. Lei n.. 13.415/2017. Altera as Leis nos 9.394, de 20 de dezembro de 1996, que estabelece as diretrizes e bases da educação nacional, e 11.494, de 20 de junho 2007, que regulamenta o Fundo de Manutenção e

Desenvolvimento da Educação Básica e de Valorização dos Profissionais da Educação, a Consolidação das Leis do Trabalho - CLT, aprovada pelo DecretoLei no 5.452, de 1 o de maio de 1943, e o Decreto-Lei no 236, de 28 de fevereiro de 1967; revoga a Lei no 11.161, de 5 de agosto de 2005; e institui a Política de Fomento à Implementação de Escolas de Ensino Médio em Tempo Integral. Disponível em: http://www.planalto.gov.br/ccivil_03/_ato20152018/2017/lei/L13415.htm. Acesso em 10 nov. 2017.

BRASIL. Ministério da Educação. Secretaria de Educação Profissional e Tecnológica. Conselho Nacional da Educação. Diretrizes Curriculares Nacionais para Educação Profissional Técnica de Nível Médio. PARECER CNE/CEB №: 11/2012 Brasília.

BRASIL. Lei n. 11.892/2008. Institui a Rede Federal de Educação Profissional, Científica e Tecnológica, cria os Institutos Federais de Educação, Ciência e Tecnologia, e dá outras providências. Disponível em: 
http://www.planalto.gov.br/ccivil_03/_ato2007-2010/2008/lei//11892.htm. Acesso em 10 nov. 2017.

CAMPOS, Roselane F.; GARCIA, Rosalba Maria C.; SHIROMA, Eneida O. Decifrar textos para compreender a política: subsídios teórico-metodológicos para análise de documentos. Revista PERSPECTIVA, Florianópolis, v. 23, n. 02, p. 427-446, jul./dez. 2005.

CIAVATTA, Maria. A formação integrada: a escola e o trabalho como lugares de memória e de identidade. Trabalho Necessário, v.3, n.3, 2005. Disponível em: http://www.uff.br/trabalhonecessario/images/TN_03/TN3_CIAVATTA.pdf. Acesso em 10 nov. 2017.

COELHO, Juçara Eller. A desvinculação dos ensinos médio e técnico na escola técnica federal de Santa Catarina - unidade Florianópolis - a partir do decreto n. . 2208/97 (1997-2004), campus Florianópolis, 2012.

FRIGOTTO. Revista Trabalho Necessário. A produtividade da escola improdutiva 30 anos depois: regressão social e hegemonia às avessas. Ano 13, número 20 - 2015. Disponível em:

http://www.uff.br/trabalhonecessario/images/TN_20/10_frigotto.pdf. Acesso em 22 mai. 2018.

GRAMSCI, Antonio. Cadernos do cárcere, caderno 13. O Príncipe Moderno. Rio de Janeiro; Ed. Civilização Brasileira, 2002. Brasileira, 1982.

GUEDES, Thais. As propostas de formação dos trabalhadores no ensino técnico subsequente: projetos pedagógicos dos cursos do IFSC, campus Florianópolis, 2016.

IFSC. Minuta do Projeto Pedagógico Institucional. Florianópolis, 2013. Disponível em: http://pdi.ifsc.edu.br/files/2013/08. Acesso em 29 mar. 2018.

IFSC. Ata da Assembleia Geral para apreciação do PPI. Florianópolis, 2018. Disponível em: http://cs.ifsc.edu.br. Acesso em 08 jun. 2018.

IFSC. Diretoria de Ensino. Relatório de inconsistências frequentes na criação/alteração de PPCs do IFSC. Mensagem recebida por evandro.belmiro@ifsc.eadu.br em15 mar 2018.

IFSC. COLEGIADO DE ENSINO, PESQUISA E EXTENSÃO. Disponível em: http://pdi.ifsc.edu.br/files/2013/08. Acesso em:08 jun. 2018.

ILLICH, Ivan. Por que devemos desinstalar a escola. Sociedade sem escolas: trad. de Lúcia MathildeEndlich Orth. Petrópolis, Vozes, 1985.

KONDER, Leandro. O que é dialética. São Paulo: Brasiliense, 2008.

Disponível em: «. Acesso

em:http://afoiceeomartelo.com.br/posfsa/Autores/Konder,\%20Leandro/O\%20qu e\%20e\%20dialetica.pdf. Acesso em 02 jun. 2019. 
NOGUEIRA, Cláudio Marques Martins; NOGUEIRA, Maria Alice. A Sociologia da Educação de Pierre Bourdieu: limites e contribuições. Revista Educação \& Sociedade, ano XXIII, no 78, Abril/2002

RAMOS, Marise. Trabalho, educação e correntes pedagógicas no Brasil: um estudo a partir da formação dos trabalhadores técnicos da saúde. Rio de Janeiro: EPSJV, UFRJ 2010. 290 p.

RAMOS, Marise. Concepção do Ensino médio integrado. Pará, Secretaria de Estado da Educação, 2008. Disponível em:

http://www.iiep.org.br/curriculo_integrado.pdf. Acesso em 10 nov. 2017.

RAMOS, Marise. Ensino Médio Integrado: lutas históricas e resistências em tempos de regressão. In: Ensino médio integrado no Brasil: fundamentos, práticas e desafios / - Brasília: Ed. IFB, 2017. Disponível em:

http://forum.anped.org.br/sites/default/files/images/livro_completo_ensino_medi o_integrado_-_13_10_2017.pdf. Acesso em 02 jun. 2019.

RAMOS, Marise; CIAVATTA, Maria. A "era das diretrizes": a disputa pelo projeto de educação dos mais pobres. Revista Brasileira de Educação v. 17 n. 49 jan.abr. 2012.

RODRÍGUEZ, Margarita Victoria. Pesquisa Social - contribuições do método materialista histórico-dialético. In: DA CUNHA, Célio; DE SOUSA, José Vieira; DA SILVA, Maria Abádia (org.). O método dialético na pesquisa em educação. Campinas: Autores Associados, 2014.

SIMÕES, Carlos Artexes. Educação técnica e escolarização de jovens trabalhadores. In: MOLL, Jaqueline. Educação profissional e tecnológica no Brasil Contemporâneo: desafios, tensões e possibilidades. Porto Alegre: Artmed, 2010.

SAVIANI, Dermeval. ORIGEM E DESENVOLVIMENTO DA PEDAGOGIA HISTÓRICO-CRÍTICA. Disponível em:

https://www.ifch.unicamp.br/formulario_cemarx/selecao/2012/trabalhos/Demerv al\%20Saviani.pdf. Acesso em 22 mai. 2018.

SAVIANI, Dermeval. Pedagogia histórico-crítica: primeiras aproximações/Dermeval Saviani. 11.ed. rev. Campinas, SP: Autores Associados, 2011. - (Coleção educação contemporânea).

VASCONCELLOS, Celso dos S. Planejamento: projeto de ensinoaprendizagem e projeto político-pedagógico. 4⿳亠口冋. Parte PROJETO POLÍTICOPEDAGÓGICO. Disponível em:

http://moodle.educacao.rs.gov.br/pluginfile.php/20346/mod_resource/content/1/ Projeto_Politico_Pedagogico\%20Vasconcellos.pdf. Acesso em 22 mai. 2018.

VEIGA, IIma Passos Alencastro. Projeto político-pedagógico: novas trilhas para a escola. In: VEIGA, Ilma Passos Alencastro; FONSECA, Marília (orgs.). As dimensões do projeto político-pedagógico: Novos desafios para a escola. Campinas, SP: Papirus, 2001. - (Coleção Magistério: Formação e Trabalho Pedagógico).

VEIGA, IIma Passos Alencastro. Projeto Político-Pedagógico e gestão democrática. Novos marcos para a educação de qualidade. Disponível em: 
http://retratosdaescola.emnuvens.com.br/rde/article/viewFile/109/298. Acesso em 22 mai. 2018.

VEIGA, IIma Passos Alencastro. PROJETO POLÍTICO-PEDAGÓGICO DA ESCOLA: UMA CONSTRUÇÃO COLETIVA. Disponível em: http://pep.ifsp.edu.br/wpcontent/uploads/2015/01/PPP-uma-constru\%C3\%A7\%C3\%A3o-coletiva.pdf. Acesso em 22 mai. 2018.

VEIGA, IIma Passos Alencastro; FONSECA, Marília (orgs.). As dimensões do projeto político-pedagógocio. Campinas, SP: Papirus, 2001. 5aㅡ edição. Coleção Magistério: Formação e Trabalho Pedagógico.

VEIGA, IIma Passos Alencastro; RESENDE, Lúcia Maria Gonçalves (orgs.). Escola: Espaço do projeto político-pedagógico. Campinas, SP: Papirus, 1998. Coleção Magistério: Formação e Trabalho Pedagógico. 